\title{
NOTAS SOBRE ONTOLOGIA E PRÁXIS SOCIAL NO PENSAMENTO DE ANTHONY GIDDENS
}

\author{
Asher Grochowalski Brum Pereira*
}

\begin{abstract}
Resumo: Neste artigo, abordo a opção de Anthony Giddens pela ontologia e, em decorrência, a centralidade da práxis social como forma de responder à tradição da teoria social, principalmente o legado de Talcott Parsons. Analiso, por conseguinte, os pressupostos ontológicos que constituem a base da práxis giddensiana: a capacidade transformadora humana (o poder entendido no seu sentido genérico) e a reflexividade.
\end{abstract}

Palavras-chave: Anthony Giddens, Ontologia, Práxis Social, Poder, Reflexividade.

Abstract: This paper aims to analyze the Anthony Giddens's option by ontology and, in consequence, the centrality of social praxis as a form to confront the tradition of social theory, principally the Talcott Parsons's legacy. I analyze, therefore, the ontological presuppositions which constitute the basis of giddensian praxis: the human transformative capacity (the power comprehended in its general sense) and the reflexivity.

Keywords: Anthony Giddens, Ontology, Social praxis, Power, Reflexivity.

* Mestre em Sociologia. E-mail: asherbrum@yahoo.com.br 
|188|

Notas sobre Ontologia e Práxis Social...

O objetivo do artigo é fazer um itinerário teórico e interpretativo do pensamento de Anthony Giddens e, dessa forma, compreender a opção do autor pela ontologia como ponto de partida para a construção do seu quadro teórico. O exame dessa problemática justifica-se pelo fato da opção ontológica daquele autor, que culminou na teoria da estruturação, permitir que o mesmo se posicione frente ao debate sociológico do seu tempo, e, além disso, assuma uma posição própria e inovadora na discussão. A ontologia é o meio pelo qual o autor ataca o problema fundacional da teoria social do século XX: a relação entre agência e estrutura. Portanto, a teoria da estruturação é essencialmente ontológica, calcada numa concepção clara de práxis, a qual, segundo entendo, se assenta em dois pressupostos ontológicos: a capacidade transformadora humana (o poder entendido no seu sentido genérico) e a reflexividade.

Giddens, assim como Jürgen Habermas, Pierre Bourdieu, Randall Collins e outros, enquadra-se no que Alexander (1986) chamou de "Novo Movimento Teórico". Esse movimento surgiu como uma clara ofensiva à unilateralidade insustentável, em voga, principalmente, até a década de 70, que dividia o pensamento social entre escolas de micro e de macroteoria. O "Novo Movimento Teórico", por sua vez, entendia que essas duas esferas precisavam ser articuladas e, desse modo, passaram a buscar uma síntese. O movimento, até hoje, apresenta seus principais representantes na Inglaterra, Alemanha, França e Estados Unidos. Em se tratando especificamente de Giddens, a importância cabal do seu projeto para o debate contemporâneo é a tentativa de superar o legado de Talcott Parsons, que se lançou à busca da síntese ainda na década de 1930, através da proposta de uma ontologia das práticas sociais e da vida social. Parsons procurou estabelecer princípios metafísicos universais como ponto de partida da sua teoria, mas caiu no erro determinista de lançar-se à busca de comprovações empíricas que legitimassem seus princípios metafísicos para, assim, como sugere a linha positivista na qual Parsons se insere, fugir da metafísica. 
O "Novo Movimento Teórico", segundo Alexander, caracteriza-se pela formulação de teorias gerais, sem referencia empírica direta. Desse modo, comenta Alexander (1986),

\begin{abstract}
Por pressupostos (...), entendo as suposições mais gerais que os sociólogos fazem quando se defrontam com a realidade. Cada teoria social e cada trabalho empírico tomam posições a priori que permitem que os observadores organizem nas categorias mais simples os dados dos sentidos que entram em suas mentes. E é só nessa base que são possíveis as manipulações mais conscientes que constituem o pensamento racional ou científico. Os pressupostos são objetos do discurso, e são até mesmo discursivamente justificados. Em sua maioria, contudo, se originam em processos que precedem ao próprio exercício da razão.
\end{abstract}

Utilizo, aqui, o termo "pressupostos", no sentido que Alexander (1986) atribui ao termo, para referir-me aos princípios ontológicos que norteiam toda a teoria giddensiana da estruturação. A construção de uma teoria geral é muito patente em Giddens, o que deu origem às críticas que afirmar que a teoria da estruturação torna-se problemática quando aplicada ao universo empírico. Portanto, proponho uma incursão pelo pensamento giddensiano tendo como eixo de análise a ontologia presente em sua teoria. Mais do que isso, identifico os dois pressupostos ontológicos essenciais do seu pensamento que irão culminar na concepção estruturacionista da práxis.

O que é essencial, aqui, é compreender o itinerário teórico do pensamento giddensiano, que parte de uma construção praxiológica calcada em princípios ontológicos, para, daí, desenvolver preocupações empíricas próprias da sociologia. A trajetória do pensamento giddensiano apresenta uma clara base ontológica, metafísica, e é necessário compreendê-la para, num segundo momento, pensar as limitações dos seus postulados empíricos. 
|190|

Notas sobre Ontologia e Práxis Social...

Em suas considerações críticas acerca do projeto de Anthony Giddens, Bauman (1989) afirma que esse autor ocupa uma posição própria, só dele, na teoria social contemporânea. De fato, a obra de Giddens tem uma proposta muito sóbria e objetiva: a atualização, a reconstrução e a revisão crítica (a "crítica positiva" - Giddens, 1996) da teoria social dos séculos XIX e XX, e, desse modo, formular um quadro teórico-metodológico capaz de abordar analiticamente a modernidade e, também, apto a teorizar sobre a atividade social humana. Essa linha mestra orienta a sua obra desde 1970, com a publicação de seus trabalhos críticos sobre a sociologia clássica, até o final do século XX, com a publicação de sua suma teórica - A Constituição da Sociedade (1984) - e de seus trabalhos sobre a modernidade. Há originalidade, e também muita polêmica, em torno do ambicioso projeto giddensiano, e muitos pontos são frágeis à crítica.

O conjunto da obra de Giddens representa uma reavaliação crítica do saber teórico acumulado na teoria social e na sociologia e, desse modo, o autor propõe a articulação de um novo quadro teórico-metodológico, a chamada teoria da estruturação. Segundo Bauman (1989), o projeto de Giddens é integrar a teoria social de modo a possibilitar uma unidade que as teorias social e sociológica nunca desfrutaram. Por conseguinte, Giddens procura englobar positivamente as contribuições da tradição sociológica e da teoria social, ao passo que submete a duras críticas o que julga inadequado. De fato, o projeto giddensiano tem por intuito travar o consenso na sociologia e na teoria social que Parsons não foi capaz de alcançar, no início do século XX, embora fosse seu projeto fazê-lo. Eis aí o grande desafio em que Giddens está inserido: fazer uma teoria que englobe a tradição sociológica e a teoria social sem, com isso, voltar ao passado.

\section{A opção ontológica}

A teoria da estruturação, tal como é exposta e sistematizada em As novas regras do método sociológico (1976), em Central problems in social theory (1979) e, principalmente, em A constituição da sociedade 
(1984) pode ser entendida como enunciados claros de um determinado tipo de ser, ou seja, são proposições ontológicas. Ira Cohen (1996) considera que a opção giddensiana pela ontologia se deu com o intuito de formular uma teoria social diferenciada do positivismo, do funcionalismo e do evolucionismo. Ao propor uma concepção acerca de um tipo de ser, ou seja, ao propor uma ontologia, Giddens afasta-se dos debates em teoria social com preocupações epistemológicas sobre as formas do conhecimento. Isso demonstra, sem dúvida, uma preocupação maior com o objeto da sociologia, o homem e suas práticas, do que com os métodos para conhecer os princípios universais constituidores desse homem. Desse modo, Giddens (2009) considera que a teoria social, orientada por preocupações ontológicas, pode inspirar teorias a partir das próprias práticas sociais e servir como ponto de partida para pesquisas empíricas.

A teoria da estruturação é, antes de tudo, uma concepção praxiológica da vida social e dos seus desdobramentos. A problemática fundante dessa teoria reside, essencialmente, sobre a interação entre agência e estrutura como elementos estruturantes das práticas sociais cotidianas. Mais do que a incidência de uma sobre a outra, Giddens (1996; 2009) constrói um quadro teórico que aborda esses dois elementos como mutuamente determinantes, ao invés de atribuir exclusividade a uma dessas esferas. Para tanto, o autor retoma uma discussão que sempre esteve presente na agenda das ciências sociais desde a sociologia clássica: o antagonismo entre objetivismo e subjetivismo. Giddens (2009) retoma essa discussão para propor uma solução a partir da teoria da estruturação. A contribuição essencial desse autor para a discussão da relação objetivismo/ subjetivismo é pensar agente (esfera subjetiva) e estrutura (esfera objetiva), não como uma dicotomia, mas como mutuamente complementares. Giddens (2009) concebe agência e estrutura como uma dualidade, o que implica que as esferas subjetiva e objetiva sejam, ao invés de excludentes, complementares entre si. Ao inserir a ideia de dualidade da estrutura, Giddens procura atribuir o mesmo grau de importância tanto a uma quanto à outra. $\mathrm{O}$ autor 
|192|

Notas sobre Ontologia e Práxis Social...

propõe uma sistematização de conceitos na teoria da estruturação que se referem à produção e à reprodução da vida social e, ao mesmo tempo, engaja-se no ambicioso projeto de adaptar a teoria social às condições modernas. Esses conceitos estão relacionados com a constituição do ser social e com a inserção do mesmo na práxis.

Por meio de sua opção ontológica, Giddens distancia-se da tradição do positivismo que procura renegar a associação da vida social com princípios metafísicos abstratos, ou seja, que não podem ser comprovados empiricamente. Por outro lado, a teoria da estruturação não deixa de propor mecanismos metafísicos reguladores da vida social em geral, por mais plásticos e flexíveis que sejam. Princípios como a monitoração reflexiva da ação e a capacidade transformadora humana não deixam de ser princípios metafísicos universais da concepção giddensiana de ser, embora sejam moldáveis de acordo com o contexto histórico. Giddens, evidentemente, não propõe princípios metafísicos externos ao ser, mas são princípios constituidores do ser, inatos a todo homem. A concepção giddensiana de ser vai ao encontro do pensamento de filósofos da ciência, como Karl Popper (2007) e Thomas Kuhn (1975), que reconhecem que o processo de conhecimento científico é impossível sem partir de uma fé em princípios metafísicos que não se justificam de um ponto de vista empírico. Também Roy Baskhar (1979), uma das principais influencias de Giddens, defende que existem "objetos intransitivos" na vida social, ou seja, princípios metafísicos que influenciam a vida social e que estão além da empiria. Frederic Vandenberghe (2010) é claro ao demonstrar que o realismo crítico se propôs a recuperar as bases ontológicas da teoria social e essa é a influencia fundamental de Baskhar na teoria giddensiana. Em Giddens (1996), também é explícito o ponto de vista husserliano que remete a uma filosofia que transcende o conhecimento empírico. Afirma Giddens (1996), ao comentar este último autor, que a epistemologia implica a ontologia, pois o conhecimento implica o ser.

A forma como Giddens (1996) formula a sua opção pela ontologia, antes de tudo, permite que o autor trave uma cisão 
entre a teoria da estruturação e as teorias sociais que acreditam existir uniformidades históricas e leis universais da sociedade. A corrente teórica que trabalha com uniformidades históricas e leis universais é fortemente vinculada às ciências naturais, e tem Parsons como um de seus principais divulgadores. Os teóricos das uniformidades históricas acreditam que existem princípios que não são históricos, mas sim trans-históricos, que conduzem a história humana. Esses princípios e leis universais, segundo esses teóricos, são empiricamente comprováveis e devem ser o objeto dos estudos da sociedade. Assim como nas ciências naturais, os teóricos da uniformidade acreditam que existem regularidades naturais que organizam a história, de tal sorte que acreditam que sob as mesmas condições naturais as circunstâncias históricas tendem a ocorrer de maneiras similares.

Giddens assume uma posição diferente e procura se distanciar das teorias que buscam generalizações e uniformidades históricas. Em primeiro lugar, o autor formula pressupostos metafísicos, não verificáveis empiricamente, como ponto de partida da teoria da estruturação. Esses princípios abstratos, constitutivos do ser, são gerais, uma vez que são constitutivos de todo e qualquer ser. Mas, Giddens estabelece tais princípios apenas como premissa de onde parte a sua explicação. Ao conceber o homem como um ser dotado de capacidade transformadora - o poder de obter resultados com a sua ação, Giddens atribui ao ser, o agente social, a capacidade de produzir e interferir no curso dos eventos. Portanto, para Giddens (2009), a história não é produto de leis universais empiricamente comprováveis, mas é produzida pelos homens a partir de sua ação na realidade. Daí decorre que não há, em Giddens, a preocupação epistemológica acerca de como conhecer essas leis universalmente dadas. Por isso, os pressupostos ontológicos propostos por Giddens distanciam-se das preocupações epistemológicas dos positivistas e dos demais teóricos das uniformidades sociais. Giddens não propõe mecanismos ou leis universais de mudança social, mas propõe premissas metafísicas, ontologicamente flexíveis, da constituição 
do ser que age historicamente. Acima de tudo, em Giddens (1996; 2009) a conduta humana está sob o controle do agente, de tal sorte que ele poderia ter agido diferente em qualquer momento de seu fluxo de ação, e não sob o controle de leis naturais empiricamente cognoscíveis.

Giddens propõe enunciados, não somente para um certo tipo de ser, mas para um ser social. Por sua "flexibilidade ontológica" (Cohen, 1996, p. 403) o ser giddensiano não é rígido, mas, pelo contrário, é um ser moldável de acordo com o contexto histórico em que está inserido. Novas configurações históricas tratam de moldar o ser giddensiano no próprio processo de mudança social, de tal sorte que ele se adapte a elas. Desse modo, a forma como o ser social, ontologicamente dado, se constitui é através da práxis social. É através da práxis que o ser psicofisicamente dado se torna ser social, ou agente social. Como fica claro em As novas regras do método sociológico, a vida social é entendida na teoria da estruturação como práxis contínua.

O ser estruturacionista pode ser chamado de ser social porque todo indivíduo já nasce em determinado contexto historicamente dado. Nenhum indivíduo começa a sua vida do zero, mas ele já está inserido, e se constitui, em relações de interação com outros indivíduos. De acordo com o contexto em que o indivíduo nasce ele vai ser moldado socialmente, graças à flexibilidade que Giddens confere aos pressupostos ontológicos constituidores do ser. Mas, ao mesmo tempo em que vai ser moldado pelo contexto, também o ser será responsável por transformar esse mesmo contexto.

Giddens propõe dois pressupostos ontológicos fundamentais que são os princípios centrais da práxis social da teoria da estruturação. São eles a reflexividade (ou monitoração reflexiva) e a capacidade transformadora humana (ou o poder de obter resultados). A capacidade transformadora humana é a categoria primordial, da qual decorre a reflexividade. A capacidade transformadora é representada pelo poder, numa concepção genérica, que é condição para a existência humana. Essa capacidade independe da configuração histórica ou da formação 
social em que o homem está inserido, e é a forma do ser organicamente dado relacionar-se com o meio natural e social e, dessa forma, tornar-se ser social. Mas, ao pôr em prática a sua capacidade transformadora, o homem também está sujeito a modificar-se a si mesmo, e é daí que surge a segunda categoria central da práxis giddensiana: a reflexividade.

Ao tomar consciência de si mesmo como agente, transformador da realidade e capaz de provocar determinados resultados, o homem desenvolve a reflexividade na esfera subjetiva. A reflexividade, segundo entendo, é a autoconsciência e o autoconhecimento que provêm dos sentidos da constituição psicofísica do homem, entendido enquanto agente social. O ponto de partida da reflexividade é a consciência de si mesmo enquanto agente transformador da realidade, ou seja, enquanto homem dotado do poder de obter resultados. Mas, também, é o autoconhecimento da própria ação, ou seja, o conhecimento tácito de como empregar a própria capacidade transformadora, ou de como prosseguir nos diferentes contextos da vida social para obter os resultados desejados ou intencionados.

Esses dois pressupostos ontológicos, constituidores da práxis social, são pressupostos abstratos. No entanto, não se propõem a ser princípios naturais, derivados de leis universais e tampouco são empiricamente comprováveis. Apesar de partir desse axioma calcado em pressupostos metafísicos, Giddens não defende que a função das ciências sociais seja desvendar ou comprovar empiricamente a existência de tais pressupostos. Para ele, esses são apenas princípios abstratos dos quais parte a teoria da estruturação. Esse, no meu entendimento, é a grande diferença entre Giddens e os positivistas e demais adeptos das uniformidades históricas.

\section{A práxis social encontrada:}

O enunciado ontológico giddensiano acerca do poder dos indivíduos de obter determinados resultados é uma ofensiva ao 
|196|

Notas sobre Ontologia e Práxis Social...

determinismo estrutural de Parsons, como fica explícito na introdução de $A$ constituição da sociedade, e a questão do indivíduo transformador é o principal postulado da teoria da estruturação. Mas, ao mesmo tempo, Giddens não ignora a não aleatoriedade ou, melhor dizendo, a regularidade - de determinadas práticas sociais. Giddens tenta se colocar além da discussão polarizada entre ação e estrutura, pois o seu projeto é de conciliação.

Segundo Popper (2007), é impossível existir uma teoria que não parta de axiomas, ou seja, de princípios metafísicos sem comprovação empírica. Parsons tomou o caminho inverso ao tentar comprovar empiricamente os princípios metafísicos que propôs, além de ter caído no determinismo estrutural regulado por leis gerais e empiricamente verificáveis. Giddens, por outro lado, parece ter assumido abertamente a máxima popperiana ao propor princípios ontológicos de um tipo específico de ser e, desse modo, construir sua análise das práticas sociais e da vida social. Em meu entendimento, essa é a grande resposta de Giddens a Parsons: a formulação de uma teoria metafísica, abstrata, que não busca comprovação empírica para seus enunciados ontológicos, nem propõe leis gerais que devem ser verificadas na história pelas ciências sociais. Importante ressaltar que, num segundo momento, Giddens recorre a princípios epistemológicos quando se trata de analisar as práticas sociais historicamente situadas. A teoria da estruturação, portanto, parte de enunciados ontológicos, princípios metafísicos gerais, acerca da constituição de um determinado tipo de ser. Mas, isso não significa que Giddens não se preocupe com problemas epistemológicos com relação às formas de conhecer as práticas sociais dos agentes historicamente situados.

A ontologia do ser social pode ser entendida a partir da inserção do agente humano na relação dualista entre agência e estrutura, em última instância dialética. Essa relação dualista, estratificada em duas partes mutuamente determinantes, é o universo no qual se dá a constituição e a reformulação do agente humano, assim como do fazer humano. A ontologia dualista da teoria da estruturação pode ser traduzida em termos da relação 
entre cultura e capacidade transformadora, ou seja, entre estrutura e agência.

A reprodução da sociedade é o produto da ação intencional do agente humano em sua vida cotidiana, mas, ao mesmo tempo, relaciona-se com consequências não premeditadas que culminam na reprodução não intencional da estrutura. Essas consequências, por sua vez, dão, como condições não reconhecidas para a ação, possibilidades para a continuidade das ações cotidianas. $\mathrm{O}$ agente humano, o ser social, se insere no contexto da vida social como um ser autoconsciente, dotado de cognoscitividade, mas que está inserido em uma rede de significações que constituem a sociedade como um todo coeso e dotado de sentido. Essas significações é que são reproduzidas diariamente pelos agentes nas atividades diárias da vida cotidiana e, ao mesmo tempo, indicam-lhes os padrões de ação a serem assimilados.

A capacidade transformadora perpassa toda a ontologia giddensiana, na forma do poder entendido em sentido genérico. Dito de outra forma, o poder, enquanto capacidade transformadora, é pressuposto para que se formule uma ontologia do ser social. O poder é fundamental para entender-se a ontologia presente na teoria da estruturação. A constituição do indivíduo enquanto ser social, a partir da teoria da estruturação, pode ser compreendida através da inserção dele no âmbito da vida cotidiana. Dito em outros termos, o indivíduo só existe e se reconhece enquanto ser social, ou agente, a partir da sua inserção, através da sua ação, na relação mutuamente determinante entre agência e estrutura. Consciência e percepção, psique e fisiologia, são elementos fundamentais para que o ser se constitua como ser social, ou agente, no âmbito da dualidade agência/estrutura.

A ontologia da teoria da estruturação está profundamente calcada na práxis social. Toda a vida social é gerada na e através da práxis. A ontologia estruturacionista procura oferecer enunciados para a constituição do ser enquanto agente, capaz de produzir resultados através de sua capacidade transformadora. O ser, na teoria da estruturação, é plástico e adaptável aos diferentes contextos, de tal sorte que se configura no próprio 
desenrolar da vida social; isto é, o ser se estrutura na dinâmica da práxis. Chamo, portanto, a teoria da estruturação de ontologia do ser social pelo fato dela apresentar essa concepção modelável do ser, que tem por princípio ontológico universal a capacidade humana genérica de agir através de sua capacidade transformadora. O que fica explícito na teoria da estruturação é que as práticas sociais e o próprio ser estão sujeitos à mudança. O ser social se constitui na e através da práxis, na qual produz e reproduz constantemente a sua ação em condições espacial, temporal e historicamente dadas. A teoria da estruturação não concebe práticas sociais que sejam a-históricas. Desse modo, é que se constitui toda vida social.

A vida social se constitui na e através da práxis, ao passo que o próprio agente também se constitui nesse âmbito, pois é ele quem constitui a vida cotidiana e transforma as circunstâncias históricas. Mas, ao passo que o agente modifica as circunstâncias nas quais está inserido, modificam-se os pressupostos constituidores da práxis, como ocorre, por exemplo, na transição das organizações sociais pré-modernas para a sociedade moderna. No entanto, existem configurações de grande extensão espaçotemporal que mantém os pressupostos da práxis como os mesmos ao longo do tempo e das gerações, e isso faz com que as práticas sociais se institucionalizem e permaneçam "as mesmas" (Giddens, 2009, p. 3) por determinado período histórico. Essas configurações são um conjunto de regras, significados e recursos que constituem as estruturas sociais de determinado sistema social em um dado período histórico. A agência e a estrutura, por conseguinte, entrelaçam-se para estruturar a práxis de determinada época e em determinado contexto e, dessa forma, constituir a vida social.

Elaborar a teoria da estruturação de forma ontológica, sem estabelecer leis empiricamente verificáveis para a constituição da vida social e através de uma concepção praxiológica flexível, é o que permite que Giddens formule críticas contundentes às leis universais presentes na teoria de Parsons. Não obstante, fica claro na teoria da estruturação que Giddens procura fugir das 
formulações teóricas universais que se lançam à busca de comprovações empíricas da sua efetividade. $\mathrm{O}$ fato do autor estabelecer regularidades históricas não significa que ele formule uniformidades trans-históricas que envolvam a produção e reprodução de práticas sociais.

Em As novas regras do método sociológico, Giddens (1996, pp. 117-118) afirma que não há sistematicidade ou uma elaboração precisa da práxis social na obra de Marx, mesmo reconhecendo que esse autor tem uma concepção ontológica da produção e reprodução da vida social. Apesar disso, entendo a práxis da teoria da estruturação afinada com a concepção de Marx (1996), que define a práxis social como a relação dialética entre a consciência e a prática. Para Marx (1996, p. 12) a práxis social é "a consciência da modificação [ou da transformação] das circunstâncias com a atividade humana". De fato, a concepção praxiológica da teoria da estruturação vai por essa via, ao passo que a ação (o poder de obter resultados) é anterior à subjetividade e, desse modo, à própria reflexividade. Através da consciência que têm da própria ação e das práticas sociais, os agentes constroem subjetivamente, por meio da reflexividade, conceitos gerais ${ }^{1}$ que orientarão a reprodução de práticas antigas. O que chamo de conceitos gerais são as razões subjetivas para a realização de práticas regularizadas e funcionam como uma espécie de entendimento teórico acerca da própria ação. É a sistematização formal desses conceitos que constitui a sociologia enquanto ciência e que gera as teorias sociais.

A consciência acerca da própria ação e das próprias práticas não existe, por certo, desenraizada da materialidade. Pelo contrário, a consciência brota da ação prática do agente, assim

\footnotetext{
${ }^{1}$ Entendo por conceitos gerais certos padrões de ação assimilados na consciência prática do agente e que servirão para a formulação de razões, pelo agente, acerca da própria ação. Esses conceitos gerais surgem na práxis e são uma espécie de entendimento teórico do agente sobre a própria ação.
} 
$|200|$

Notas sobre Ontologia e Práxis Social...

como a reflexividade a que a consciência se relaciona. Ao passo que essas práticas sociais são reproduzidas de forma consciente portanto reflexiva - por longas extensões espaçotemporais, ou seja, tornam-se regularizadas, elas convertem-se em instituições sociais. Essas instituições sociais - que nada mais são do que práticas sociais enraizadas no tempo-espaço -, por sua vez, configuram-se em propriedades estruturais (ou estruturas) dos sistemas sociais. Para Giddens (1996; 2009), portanto, a reprodução das práticas sociais é um ato consciente e reflexivo, ao passo que o agente poderia agir de qualquer outra forma no curso de um certo fluxo de ação. No entanto, apesar da liberdade de que goza o agente no fluxo de ação, a manutenção da segurança ontológica ${ }^{2}$ é um elemento fundamental na institucionalização das práticas sociais.

A práxis, portanto, se constitui por meio da ação humana e das condições espaçotemporais e históricas geradas pela agência, ao mesmo tempo em que a agência se constitui na e através dessa mesma práxis, a qual envolve toda a ação consciente e produtora de resultados pela capacidade transformadora humana. Nesse sentido, a práxis também está relacionada com a produção de conhecimento acerca da própria ação. Isso não quer dizer, evidentemente, que todo agente tenha um conhecimento formal acerca de sua própria ação. Giddens (1996; 2009), ao tratar desse conhecimento, refere-se ao conhecimento tácito produzido no âmbito da práxis, ou seja, trata-se de um saber acerca de como proceder. Esse conhecimento tácito, tal como compreendo, entrelaça-se à consciência prática do agente. $\mathrm{O}$ agente, por sua vez, pode não conseguir expressar verbalmente as razões de sua ação. O conhecimento acerca da própria ação tem a ver com a

\footnotetext{
${ }^{2}$ A segurança ontológica é a confiança em que o mundo social permaneça o mesmo ao longo do tempo, reduzindo a sensação de ansiedade. Nas palavras de Giddens (2009, p. 444), é a "confiança em que os mundos natural e social são o que parecem ser, incluindo os parâmetros sociais básicos do self e da identidade social".
} 
consciência, desenvolvida na práxis, do próprio poder de obter resultados e desencadear consequências.

Entendo que a práxis estruturacionista possui dois pressupostos essenciais e que estão entrelaçados: o poder (enquanto capacidade transformadora ou de obter resultados) e a reflexividade (enquanto consciência e conhecimento acerca da própria ação). O poder, como já abordei, na concepção genérica aplicada por Giddens (1996; 2009), refere-se à capacidade transformadora humana ou ao poder de obter determinados resultados. Esse é o conceito constitutivo que está no cerne de toda a teoria da estruturação (juntamente com a reflexividade), porque é, sobretudo, a capacidade humana de fazer a diferença, de agir deste ou daquele modo, que está na base da ontologia giddensiana. $\mathrm{O}$ ser somente existe enquanto ser social graças à sua capacidade transformadora. Na teoria da estruturação, por conseguinte, o agente sempre tem o controle, em maior ou menor grau, das suas intervenções no mundo material, e isso delega relativa liberdade ao agente. Isso significa que o agente não responde automaticamente a determinações da estrutura. $O$ agente goza tanto de liberdade quanto sofre coerções em contextos específicos. Isso é relativo tendo em vista a particularidade contextual e histórica de que se está tratando. Não existe, em Giddens, um determinismo da liberdade da ação, assim como não existe um determinismo da coerção estrutural. Giddens tenta fugir desses extremos, e acredito que ele consiga transitar bem entre os dois polos. A célebre frase de Marx (2006, p. 15) ilustra esse ponto:

Os homens fazem sua própria história, mas não a fazem segundo a sua livre vontade; não a fazem sob circunstâncias de sua escolha e sim sob aquelas com que se defrontam diretamente, legadas e transmitidas pelo passado.

Do ponto de vista de Giddens (2009), os atores historicamente localizados têm poder, através de sua capacidade transformadora, de transformar e "fazer" a própria história. No 
|202|

Notas sobre Ontologia e Práxis Social...

entanto, de acordo com o contexto envolvido em circunstâncias históricas, os homens também sofrem coerções estruturais em maior ou menor grau. A estrutura, segundo a definição giddensiana, representa um acúmulo de significados, valores e práticas sociais institucionalizas que persistem por longas extensões espaçotemporais, orientando as práticas e ações das gerações presentes e futuras. $\mathrm{O}$ zelo pela manutenção da segurança ontológica faz com que a estrutura assuma um caráter coercitivo, não permitindo que a liberdade total de ação impere colocando em risco, desse modo, a vida social tal como ela é. No entanto, claro está, a história é feita pela ação dos homens e por sua livre vontade, pois eles têm a liberdade de agir de outro modo em qualquer estágio do curso de sua ação. A coerção representa uma forma de manter a vida social tal como ela é e, além disso, representar interesses seccionais.

A capacidade de intervenção humana, o poder de obter resultados, é ativada na produção e reprodução das práticas sociais cotidianas. Essas práticas sociais, evidentemente, "fazem uma diferença" (Giddens, 2009) no desenrolar da vida social; entrelaçam-se cotidianamente no bojo da vida social, com as práticas desenvolvidas por outros agentes. Ira Cohen (1996, p. 12) chama esse "saber como agir" que envolve as práticas sociais de "habilidades praxiológicas". É o conhecimento e a consciência dessas habilidades que faz a reflexividade emergir como um tema central na ontologia da teoria da estruturação. A reflexividade constitui o outro eixo da práxis estruturacionista, ao lado da capacidade transformadora humana. Giddens (1996, p. 14) deixa claro que entende a reflexividade como uma qualidade da ação humana em geral, ou seja, como um princípio metafísico trans-histórico.

A reflexividade, por sua vez, refere-se à consciência e ao conhecimento que os agentes têm acerca da própria ação. Não se trata da reflexão ou do conhecimento no sentido racionalista, mas de percepções que surgem a partir dos mecanismos sensoriais do corpo, entendido como unidade psicofísica. As percepções que envolvem a ação se relacionam com o conhecimento de como 
agir, como continuar, ou como obter determinado resultado. Giddens (2009) trata de um conhecimento que é compartilhado por todos aqueles que se envolvem nas práticas sociais ou que são capazes de desempenhá-las. Daí o conhecimento tácito que possibilita a existência de uma consciência prática. Importante ressaltar que, como enfatiza Giddens (1996; 2009), a reflexividade não é meramente a autoconsciência, mas também envolve o conhecimento acerca da própria ação, que dá ao agente o entendimento de como prosseguir na vida social. Daí o uso do termo "monitoração reflexiva" (Giddens, 2009). O agente está constantemente em contato com o desenrolar da própria prática, de modo a produzir conhecimento sobre ela graças à monitoração constante. Entendo, ainda, que a monitoração reflexiva também está relacionada ao caráter estrutural da dualidade da estrutura, de modo que o agente monitora a própria ação por meio de regras estruturais estabelecidas, que lhe oferecem determinados padrões de ação e que indicam formas de desvio que devem ser coagidas na vida social. O conhecimento não envolve, portanto, só a própria ação individual do agente, mas o conhecimento mútuo das regras e recursos que envolvem as práticas sociais. Em suma, a reflexividade envolve dois elementos: a autoconsciência de si mesmo enquanto agente capaz de provocar resultados e o autoconhecimento de como prosseguir, a partir da própria ação, para atingir determinado resultado.

A reflexividade tem o papel fundamental de fazer com que a ação não seja meramente a capacidade de obter resultados; é o mecanismo que está por trás de toda a ação, e representa os "porquês" do agir; é o conhecimento teórico sobre a ação. Apesar de possuir capacidade transformadora, um agente não age sem estar direta ou indiretamente motivado. Na fluidez da práxis estruturacionista, acredito que os princípios ontológicos universais sejam a capacidade transformadora e a reflexividade, embora esses dois elementos possam ser remodelados no âmbito da própria práxis, uma vez que se alterem as condições históricas na e através dessa mesma práxis. 


\section{Considerações finais}

O papel fundamental da práxis na teoria da estruturação é demonstrar a produção da vida social a partir da proposição de pressupostos ontológicos que produzem e reproduzem as práticas sociais. A teoria da estruturação é extremamente consistente quanto à sua formulação ontológica, no entanto, quando penso na questão da aplicabilidade empírica da proposta giddensiana, a impressão que tenho é que se trata de um projeto amplo e inacabado. O principal problema que vejo na formulação de uma teoria social a partir da ontologia não diz respeito à proposição de pressupostos metafísicos trans-históricos, como está pressuposto em toda ontologia. O problema reside no caráter demasiado abstrato e geral que a teoria ganha baseando-se nesse tipo de pressuposto. A dificuldade não está em partir de princípios ontológicos para a formulação da teoria; reside essencialmente em manter esses princípios como fios condutores da teoria. É essa dificuldade que Giddens enfrenta ao manter a práxis, formulada a partir de pressupostos ontológicos, no cerne da teoria da estruturação.

Giddens, de fato, não cai no dilema de Parsons, que tenta dar comprovação empírica aos princípios metafísicos transhistóricos que formulou. O dilema de Giddens, como aponta grande parte dos seus críticos, é formular uma teoria demasiado geral e com conceitos muito abstratos, dificilmente aplicáveis na esfera empírica. Essa dificuldade se dá pelo fato do autor ter construído uma concepção de práxis calcada em princípios ontológicos e a ter mantido como linha mestra da teoria da estruturação, em torno da qual se sistematizam todos os conceitos. Giddens não está preocupado com as formas epistemológicas de conhecer os princípios metafísicos universais que compõem a vida social. Não obstante, creio que na tentativa de fugir disso, o autor não consegue produzir uma teoria que leve em conta os contextos micro da vida social.

O eixo principal da minha crítica à teoria da estruturação está na relação problemática entre a ontologia da teoria da estruturação e a aplicabilidade empírica dessa mesma teoria. 
Enquanto uma ontologia, a teoria da estruturação apresenta contribuições fundamentais ao debate contemporâneo. A sua fraqueza está na proposta de aplicabilidade empírica. A teoria giddensiana é, claramente, hipotético-dedutiva, ou seja, possui conceitos abstratos, sem uma definição precisa em termos de conteúdo e aplicabilidade empírica. Na obra de Giddens não há nenhum tipo de tentativa de comprovar empiricamente os pressupostos da práxis: a reflexividade e a capacidade transformadora humana. Eles são axiomas. O problema que vejo, e que torna a proposta giddensiana muito abstrata e geral, é a formulação dos demais conceitos estruturacionistas tendo por eixo a práxis social, tal como entendo que Giddens a formula. Os conceitos propostos pelo autor são elementos que põem a práxis em movimento, mas que tem como base a reflexividade e a capacidade transformadora. No diagnóstico da modernidade, por exemplo, que constitui a grande tentativa de Giddens de dar aplicabilidade empírica à teoria da estruturação, a reflexividade e o poder norteiam todo o debate, tendo o autor, por isso, que elevar a modernidade e suas instituições ao nível abstrato, afastando-se do nível micro de análise.

\section{Bibliografia}

ALEXANDER, J. “O Novo Movimento Teórico”. RBCS, n. 4, v. 1, out. http://www.anpocs.org.br/portal/publicacoes/ rbcs_00_04/rbcs04_01. htm, acesso em 1/6/2011. 1986.

BASKHAR, R. The possibility of naturalism: A philosophical critique of the contemporary human sciences. Brighton: Harvester, 1979.

BAUMAN, Z. "Hermeneutics and modern social theory". In: HELD, David e THOMPSON, John B. (orgs.). Social theory of modern societies: Anthony Giddens and his critics. New York: Cambridge University Press, pp. 34-55. 1989. 
Notas sobre Ontologia e Práxis Social...

COHEN, I. "Teoria da estruturação e práxis social". In: GIDDENS, Anthony e TURNER, Johnathan. (orgs.). Teoria social hoje. São Paulo: Editora Unesp, pp. 393-446. 1996.

COLLINS, R. A contemporary critique of historical materialism: Power, property and the state, v. 1. Berkeley: University of California Press, 1981.

GUIDDENS, A. "Historical materialism today: An interview". In: Theory, Culture E Society, v. 1, n. 2. 1982.

Central problems in social theory: Action, structure and contradiction in social analysis. Londres: MacMillan Education LTD, 1988.

. Novas regras do método sociológico: Uma crítica positiva às sociologias interpretativas, 2a ed. Lisboa: Gradiva, 1996.

. Política, sociologia e teoria social: Encontros com o pensamento social clássico e contemporâneo. São Paulo: Unesp, 1997.

. Capitalismo e moderna teoria social, $6^{\mathrm{a}}$ ed. Lisboa: Presença, 2005.

. O Estado-nação e a violência: Segundo volume de uma crítica contemporânea ao materialismo histórico. Tradução: Beatriz Guimarães. São Paulo: Edusp, 2008. 2009a.

A constituição da sociedade. São Paulo: Martins Fontes,

. Quatro tradições sociológicas. Petrópolis: Vozes, 2009b.

GROCHOWALSKI, A. Da teoria social à modernidade: Reflexividade, poder e práxis no pensamento de Anthony Giddens. Dissertação (Mestrado em Sociologia). Universidade Estadual de Campinas. Campinas: Unicamp, 2011.

HELD, D. e THOMPSON, J. B. (orgs.). Social theory of modern societies: Anthony Giddens and his critics. New York: Cambridge University Press, 1989. 
KUHN, T. A estrutura das revoluções científicas. São Paulo: Perspectivas, 1975.

MARX, K. e ENGELS, F. A ideologia alemã. São Paulo: Hucitec, 1996.

O 18 brumário de Louis Bonaparte, 5a ed. São Paulo: Centauro, 2006.

PARSONS, T. The structure of social action. New York: The Free Press, 1966.

Social system. Londres: Routledge \& Kegan Paul, 1979.

POPPER, K. A lógica da pesquisa científica. São Paulo: Cultrix, 2007.

VANDENBERGHE, F. Teoria social realista: Um diálogo francobritânico. Minas Gerais: UFMG, 2010. 